\title{
Magnetic enhancement of the lower esophageal sphincter
}

\author{
Peter J. Kahrilas, MD \\ Department of Medicine, Northwestern University Feinberg School of Medicine, Chicago, Illinois, \\ USA
}

\begin{abstract}
Although the skeptics among us might lament, "not another GERD-device treatment," innovation within this therapeutic area must continue. Admittedly, there have been several missteps along the way, but the goal remains reasonable and has yet to be attained. There is a substantial void in GERD management strategy between antisecretory drug therapy and Nissen fundoplication begging to be filled. Some might argue that there is no need for this because Nissen fundoplication is the answer. The authors of this report point out that there were approximately 35,000 Nissen fundoplications performed in the United States in 1999, giving the suggestion that the number is still increasing. However, this is not the case. Quite the contrary, more recent tabulations show a steady decline in the number of laparoscopic Nissen fundoplications performed in the United States, from a peak of 31,695 in 1999 to 23,998 in 20031 and an estimated 18,000 in 2006 (unpublished consultants report). The explanations for the drop are numerous, but high among them is the recognition that, outside the experience reported in clinical trials and from specialty centers, practitioner satisfaction with this procedure is declining. It takes only a few bad outcomes to alter practice patterns, and there have been more than a few.2,3 Thus, from a physiological perspective, an ideal surgical/ endoscopic GERD treatment should (1) render an effect that is less severe than that of a fundoplication, and (2) be truly reversible.
\end{abstract}

In this issue of Gastrointestinal Endoscopy, Ganz et $\mathrm{al}^{4}$ describe a necklace of magnetic beads designed to be surgically placed around the esophagogastric junction (EGJ) to reinforce closure by means of the magnetic attraction between the beads. They report on extensive bench testing of the relationship between the magnetic force of the beads and the resultant gastric yield pressure, and on an in vivo feasibility study in pigs. Results of a histologic analysis performed 20 to 44 weeks after implant suggest that the beads become encapsulated in fibrous tissue over time and that no tendency to migrate was evident. The necklace in one pig was easily removed at 44 weeks to demonstrate the feasibility of doing so. The authors indicate that human trials are under way.

Gastric yield pressure was used as the main demonstration of effect in the porcine study. The technique involves ligating the pylorus and then infusing water into the stomach via a gastrotomy tube until the resistance of the EGJ is overcome and fluid exits via the esophagus. Yield pressure was increased in the pigs from a mean of $10 \mathrm{mmHg}$ to $46 \mathrm{~mm} \mathrm{Hg}$ by varying the strength of the magnets encircling the EGJ. However, it is completely unclear to me how to interpret yield-pressure data, because this measure has questionable physiological meaning. Certainly, intragastric pressure is not generally increased by $36 \mathrm{mmHg}$ under any circumstances, except perhaps projectile vomiting. In barostat experiments, an increase of 4 $\mathrm{mm} \mathrm{Hg}$ in intragastric pressure is sufficient to induce nausea in most subjects, and $6 \mathrm{~mm} \mathrm{Hg}$ is tolerated by very few.

Copyright $\odot 2008$ by the American Society for Gastrointestinal Endoscopy DISCLOSURE

The author reports that there are no disclosures relevant to this publication. 
An ideal surgical or endoscopic GERD treatment should (1) render an effect that is less severe than that of a fundoplication, and (2) be truly reversible.

Lower esophageal sphincter (LES) pressure is a more meaningful assessment of treatment effect on the EGJ than yield pressure, and this was also increased in the pigs after implant, although less consistently and more modestly (mean increase, 23 to $36 \mathrm{~mm} \mathrm{Hg}$ ). The variability observed among animals was likely attributable to the moment-to-moment fluctuations commonly observed in recording LES pressure. If possible, a better measure of treatment effect would be residual EGJ pressure during deglutitive relaxation because that measure would best isolate the EGJ closure pressure attributable to the magnetic necklace from ongoing and uncontrolled myogenic and neurogenic effects on sphincter tone. Another alternative would be to measure EGJ pressure with amyl nitrite administration, yet another way of isolating the treatment effect from super-imposed myogenic and neurogenic influences. However, by using the data in hand and assuming that this translates to a $10-$ to $20-\mathrm{mm} \mathrm{Hg}$ sphincter pressure increase in humans, it will be of great interest to see how well it is tolerated in humans. Not that this is such a great magnitude of sphincter pressure, but because it will be present irrespective of swallow-induced EGJ relaxation, it may well be associated with dysphagia in at least some individuals. The results of high-resolution manometry studies in humans establish a residual EGJ pressure of about $15 \mathrm{~mm} \mathrm{Hg}$ as the cutoff for normal findings. ${ }^{5}$ With residual pressures greater than $15 \mathrm{~mm} \mathrm{Hg}$, subjects are categorized as having functional obstruction and often report dysphagia.

Just as residual EGJ pressure during relaxation is an important consideration during swallowing, it is also important during transient LES relaxations, the mechanism of belching and a dominant mechanism of reflux in many individuals. Reflux during transient LES relaxation is usually a very low-pressure event, with gastroesophageal pressure gradients averaging about $4 \mathrm{~mm} \mathrm{Hg} .{ }^{6}$ Again, it will be of great interest to see how increasing the residual EGJ pressure by 10 to $20 \mathrm{~mm} \mathrm{Hg}$ is tolerated in humans, because it is quite conceivable that it will make it nearly impossible for some individuals to belch. This raises another consideration pertaining to the anticipated effect of the magnetic necklace on the EGJ opening once it has occurred. As the sphincter opens wider, the magnetic force will diminish, resulting in less treatment effect (the opposite of an elastic band that would exert more treatment effect with greater aperture). Existing knowledge of EGJ mechanics in reflux disease suggests that a dominant abnormality is of increased compliance, ${ }^{6}$ and that a treatment effect more akin to an elastic band would be desirable.

At the end of the day, although it is tempting to speculate how a magnetic necklace will affect the EGJ function in humans, there is no substitute for data. No animal model exists that can predict how this device will perform clinically, whether it will control reflux, or whether it will be associated with dysphagia and/or bloating. Given that limitation, the authors are to be commended for the novelty of the investigational device and the thoughtful modeling of effect they have provided thus far. Furthermore, this device has the important benefit of being a reversible intervention, something of great value given the unpredictable responses we have come to accept as par for the course when dealing with interventions targeting the EGJ.

\section{Acknowledgments}

This work was supported by grant RO1 DC00646 (PJK) from the Public Health Service.

\section{Abbreviations}

EGJ esophagogastric junction 
LES lower esophageal sphincter

\section{REFERENCES}

1. Finks JF, Wei H, Birkmeyer JD. The rise and fall of antireflux surgery in the United States. Surg Endosc 2006;20:1698-1701. [PubMed: 16960665]

2. Dire CA, Jones MP, Rulyak SJ, et al. The economics of laparoscopic Nissen fundoplication. Clin Gastroenterol Hepatol 2003;1:328-332. [PubMed: 15017676]

3. Kahrilas PJ. Laparoscopic antireflux surgery: silver bullet or the Emperor's new clothes. Am J Gastroenterol 1999;94:1721-1723. [PubMed: 10406225]

4. Ganz RA, Gostout CJ, Grudem J, et al. Use of a magnetic sphincter for the treatment of GERD: a feasibility study. Gastrointest Endosc 2008;67:287-294. [PubMed: 18226691]

5. Ghosh SK, Pandolfino JE, Rice J, et al. Impaired deglutitive EGJ relaxation in clinical esophageal manometry: a quantitative analysis of 400 patients and 75 controls. Am J Physiol 2007;293:G878G885.

6. Pandolfino JE, Shi G, Trueworthy B, et al. Esophagogastric junction opening during relaxation distinguishes non-hernia reflux patients, hernia patients and normals. Gastroenterology 2003;125:1018-1024. [PubMed: 14517784] 